\title{
Based on the background of information technology, the integration of agricultural product processing industry and green ecological industry in Gansu Province
}

\author{
Miaojing Ying ${ }^{1, *}$ \\ ${ }^{1}$ Management Science and engineering,Lanzhou University of Technology,Lanzhou,China
}

\begin{abstract}
Driven by the development of informatization, it is necessary to integrate the agricultural product processing industry and the green ecological industry in Gansu Province. The green ecological industry is the characteristic of both the integrated green industry and the informationized ecological industry. Based on the analysis of the current situation of the agricultural product processing industry in Gansu Province, this paper uses the analytic hierarchy process to select 14 indicators for measurement, and summarizes the future development potential of the agricultural product processing industry in Gansu Province according to the ranking level in 23 provinces and cities.
\end{abstract}

\section{Introduction}

After years of development and construction in Gansu Province, as of the beginning of 2018, various agricultural products processing enterprises have developed to 2,300, with agricultural product processing capacity reaching 25 million tons, and agricultural product processing rate reaching $52.5 \%$, basically forming a sound agricultural product processing system ${ }^{[1]}$. The pattern of advantageous agricultural industries in Gansu Province has been initially optimized, the scale of the agricultural product processing industry has gradually expanded, and the level of development of the agricultural product processing industry has continued to deepen. It is playing an increasingly important role in radiating and driving the construction of modern agriculture in Gansu, but there are still some problems.

\section{Introduction to the current situation of agricultural product processing industry}

First, the extension of the industrial chain is limited, and the deep processing of specialty agricultural products is insufficient. Most agricultural products have only undergone preliminary processing, and the proportion of intensive and deep processing is relatively low. There are many small processing enterprises, simple production technology, low added value, and low competitiveness. For example, $70 \%$ to $75 \%$ of potatoes in the province are directly eaten or processed; the "manor" dairy industry is only sold in the province; the conversion rate of other agricultural products is only $40 \%$ to $50 \%$ on average.

Second, the scale of the industry urgently needs to be expanded, and the degree of intensification needs to be strengthened ${ }^{[2]}$. The scale of agricultural products processing enterprises in our province is small and the overall level is still relatively low. Small-scale, multibrand decentralized operations have no advantage in competition. The vast majority of small and medium-sized enterprises have few collaterals, weak financing capabilities, and shortage of funds for purchasing raw materials, which weakens the market competitiveness of their products and the profit margins of enterprises.

Third, the level of technological innovation needs to be improved urgently, and the industrial support capacity is not strong ${ }^{[3]}$. Some imported technologies cannot match the characteristics of characteristic agricultural products, and they fail to innovate technologies based on actual conditions. The actual effects obtained by copying practices deviate from the ideal expectations. They cannot form a good industrial development support, which greatly restricts the development of Gansu's agricultural product processing industry.

Fourth, the reputation of independent brands is not high, and the driving effect of leading companies is not strong $^{[4]}$. In recent years, the initial formation of selfowned brand enterprises has weak awareness, lack of competitiveness in products, low brand value and popularity, and difficulty in capital turnover. The overall agricultural product processing technology is low, the level of information management is low, and the regional layout is conservative ${ }^{[5]}$. Leading enterprises have not been able to drive other enterprises. 


\section{Determination of the development level of industrial green integration}

\subsection{Introduction to the measurement method}

(1) AHP

Step1: Build a hierarchical model

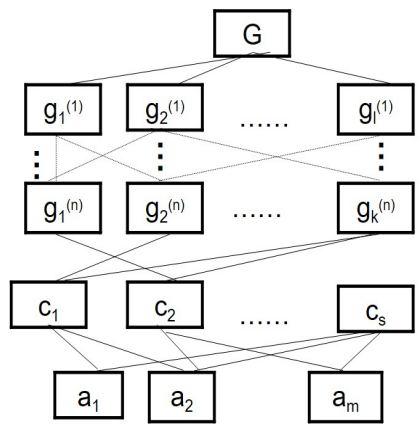
G: main target
g: Sub-target
c: Criterion layer
a: Scheme layer

\section{Step2: Construct a judgment matrix}

Compare any element $A_{i}(i=1,2, \ldots, m)$ in the first column on the left with any element $A_{j}(j=1,2, \ldots, m)$ in the first row above.,finally get the element $A_{1}, A_{2}, \ldots, A_{m}$ judgment matrix A about the criterion $\mathrm{Cr}$.

$\mathrm{a}_{\mathrm{ij}}$ : relative importance

$$
A=\left(a_{i j}\right)_{m \times m}
$$

\begin{tabular}{c|ccccc}
$\mathrm{C}_{\mathrm{r}}$ & $\mathrm{A}_{1}$ & $\ldots$ & $\mathrm{A}_{\mathrm{j}}$ & $\ldots$ & $\mathrm{A}_{\mathrm{m}}$ \\
\hline $\mathrm{A}_{1}$ & $\mathrm{a}_{11}$ & $\ldots$ & $\mathrm{a}_{1 \mathrm{j}}$ & $\ldots$ & $\mathrm{a}_{1 \mathrm{~m}}$ \\
$\mathrm{~A}_{2}$ & $\mathrm{a}_{21}$ & $\ldots$ & $\mathrm{a}_{2 \mathrm{j}}$ & $\ldots$ & $\mathrm{a}_{2 \mathrm{~m}}$ \\
$\cdot$ & $\ldots$ & $\ldots$ & $\ldots$ & $\ldots$ & $\ldots$ \\
$\cdot$ & & & & & \\
$\cdot$ & & & & & \\
$\mathrm{A}_{\mathrm{i}}$ & $\mathrm{a}_{\mathrm{i} 1}$ & $\ldots$ & $\mathrm{a}_{\mathrm{ij}}$ & $\ldots$ & $\mathrm{a}_{\mathrm{mm}}$ \\
. & $\ldots$ & $\ldots$ & $\ldots$ & $\ldots$ & $\ldots$ \\
$\cdot$ & & & & & \\
$\cdot$ & & & & & \\
$\mathrm{A}_{\mathrm{m}}$ & $\mathrm{a}_{\mathrm{m} 1}$ & $\ldots$ & $\mathrm{a}_{\mathrm{mj}}$ & $\ldots$ & $\mathrm{a}_{\mathrm{mm}}$
\end{tabular}

Step3 : Hierarchical single ranking and consistency check

All eigenvalues of judgment matrix $\mathrm{A}$

$$
\lambda_{1}=\lambda_{\mathrm{max}}, \lambda_{2}, \cdots, \lambda_{m}
$$

C.I. means Consistency Index of Judgment Matrix

$C . I=\frac{\lambda_{\max }-m}{m-1}$

The larger the C.I, the more inconsistent. On the contrary, the agreement

$$
C \cdot R=\frac{C . I}{R . I}
$$

C.R. means consistency ratio

When $C . R \leqslant 0.1$, The model passed the test.

\section{(2) TOPSSIS}

\section{Step1 : Selection of indicators}

Very small indicators: the smaller the expected indicator value, the better. The formula is as follows.

$$
\begin{aligned}
x^{\prime} & =\frac{1}{x} \quad(x>0) \\
x^{\prime} & =M-x
\end{aligned}
$$

Intermediate index: the best intermediate value.The formula is as follows.

$$
x^{\prime}= \begin{cases}2 \frac{x-m}{M-m}, & m \leq x \leq \frac{1}{2}(M+m) \\ 2 \frac{M-x}{M-m}, & \frac{1}{2}(M+m) \leq x \leq M\end{cases}
$$

Interval index: the best in a certain interval, $[\mathrm{a}, \mathrm{b}]$ is the best stable interval of index $\mathrm{X},\left[\mathrm{a}^{*}, \mathrm{~b}^{*}\right]$ is the maximum tolerance interval.

$$
x^{\prime}= \begin{cases}1-\frac{a-x}{a-a^{*}} & x<a \\ 1 & a \leq x \leq b \\ 1-\frac{x-b}{b^{*}-b} & x>b\end{cases}
$$

Step2: Construct a normalized initial matrix

This step is to make the meaning of all indicators consistent.

$$
z_{i j}=\frac{x_{i j}}{\sqrt{\sum_{i=1}^{n} x_{i j}^{2}}} \quad Z=\left[\begin{array}{cccc}
z_{11} & z_{12} & \cdots & z_{1 m} \\
z_{21} & z_{22} & \cdots & z_{2 m} \\
\vdots & \vdots & \ddots & \vdots \\
z_{n 1} & z_{n 2} & \cdots & z_{n m}
\end{array}\right]
$$

Step3: Determine the best and worst options

The optimal solution $\mathrm{Z}^{+}$is composed of the maximum value of each column element in $Z$

$$
\begin{aligned}
Z^{+} & =\left(\max \left\{z_{11}, z_{21}, \cdots, z_{n 1}\right\}, \max \left\{z_{12}, z_{22}, \cdots, z_{n 2}\right\}, \cdots, \max \left\{z_{1 m}, z_{2 m}, \cdots, z_{n m}\right\}\right) \\
& =\left(Z_{1}^{+}, Z_{2}^{+}, \cdots, Z_{m}^{+}\right)
\end{aligned}
$$

The worst scheme $Z^{-}$is composed of the minimum value of each column of elements in $\mathrm{Z}$

$$
\begin{aligned}
Z^{-} & =\left(\min \left\{z_{11}, z_{21}, \cdots, z_{n 1}\right\}, \min \left\{z_{12}, z_{22}, \cdots, z_{n 2}\right\}, \cdots, \min \left\{z_{1 m}, z_{2 m}, \cdots, z_{n m}\right\}\right) \\
& =\left(Z_{1}^{-}, Z_{2}^{-}, \cdots, Z_{m}^{-}\right)
\end{aligned}
$$

Step4: Calculate the closeness of each evaluation object to the best plan and the worst plan

$\mathrm{D}_{\mathrm{i}}^{+}$Means the distance of the best solution

$\mathrm{D}_{\mathrm{i}}^{-}$Means the distance of the worst solution

$$
D_{i}^{+}=\sqrt{\sum_{j=1}^{m} w_{j}\left(Z_{j}^{+}-z_{i j}\right)^{2}}, \quad D_{i}^{-}=\sqrt{\sum_{j=1}^{m} w_{j}\left(Z_{j}^{-}-z_{i j}\right)^{2}}
$$

Step5: Calculate and rank the closeness of each evaluation object to the optimal solution

$$
C_{i}=\frac{D_{i}^{-}}{D_{i}^{+}+D_{i}^{-}}
$$

When: $0 \leq C_{i} \leq 1, C_{i} \rightarrow 1$

$\mathrm{C}_{\mathrm{i}}$ means that the evaluation object is better.

\subsection{Construction of indicator system}

Through literature research and expert surveys, three primary indicators of environmental friendliness, hightech development, and industrial linkage have been determined, and five secondary indicators of environmental protection, resource and energy utilization, economic development benefits, technological innovation level, and industrial linkage benefits have been determined. The indicator system framework for measuring the level of green integration of the agricultural product processing industry is composed of 14 three-level indicators such as 
wastewater discharge per unit output value and agricultural product processing and conversion capacity.

\subsection{Establishment of evaluation model}

According to the indicator system of the green integration development level of the agricultural product processing industry, the evaluation model is constructed as shown in Figure 1. The index weight is determined according to the AHP method, and the results are shown in Table 1.

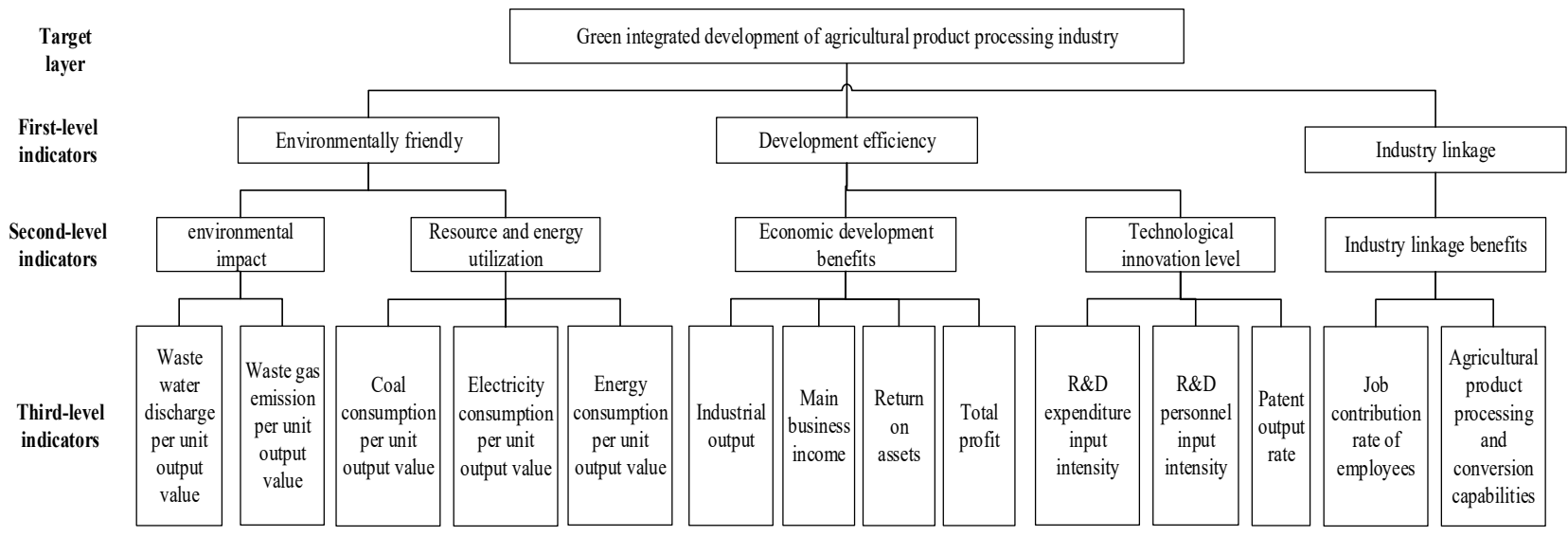

Figure 1 Evaluation model of green integration development level of agricultural product processing industry

Table 1 The weight value of the evaluation system of the green integration development level of the agricultural product processing

\begin{tabular}{|c|c|c|c|}
\hline Target & $\begin{array}{l}\text { First-level indicator } \\
\text { weight } \\
\text { (A) }\end{array}$ & $\begin{array}{l}\text { Second-level indicator } \\
\text { weight (B) }\end{array}$ & Third-level indicator weight $(\mathrm{C})$ \\
\hline \multirow{14}{*}{$\begin{array}{l}\text { Green integrated } \\
\text { development of } \\
\text { agricultural } \\
\text { product } \\
\text { processing } \\
\text { industry }\end{array}$} & \multirow{5}{*}{$\begin{array}{l}\text { Environmentally } \\
\text { friendly } \\
\text { (A1) } \\
0.490\end{array}$} & \multirow{2}{*}{$\begin{array}{c}\text { Environmental } \\
\text { protection (B1) } 0.327\end{array}$} & Wastewater discharge per unit output value ( 1 1) 0.218 \\
\hline & & & Waste gas emission per unit output value (C2) 0.109 \\
\hline & & \multirow{3}{*}{$\begin{array}{l}\text { Resource and energy } \\
\text { utilization (B2) } \\
0.163\end{array}$} & Coal consumption per unit output value (C3) 0.018 \\
\hline & & & Electricity consumption per unit output value (C4) 0.051 \\
\hline & & & $\begin{array}{l}\text { Total energy consumption per unit output value (C5) } \\
0.095\end{array}$ \\
\hline & \multirow{7}{*}{$\begin{array}{l}\text { Development } \\
\text { efficiency } \\
\text { (A2) } \\
0.312\end{array}$} & \multirow{4}{*}{$\begin{array}{c}\text { Economic development } \\
\text { benefits (B3) } 0.104\end{array}$} & Industrial output (C6) 0.007 \\
\hline & & & Main business income(C7) 0.016 \\
\hline & & & Return on assets $(\mathrm{C} 8) 0.040$ \\
\hline & & & Total profit(C9) 0.040 \\
\hline & & \multirow{3}{*}{$\begin{array}{c}\text { Technological } \\
\text { innovation level (B4) } \\
0.208\end{array}$} & R\&D expenditure input intensity $(\mathrm{C} 10) 0.044$ \\
\hline & & & R\&D personnel input intensity $(\mathrm{C} 11) 0.050$ \\
\hline & & & Patent output rate(C12) 0.114 \\
\hline & \multirow{2}{*}{$\begin{array}{c}\text { Industry linkage } \\
\text { (A3) } \\
0.198 \\
\end{array}$} & \multirow[b]{2}{*}{$\begin{array}{l}\text { Industry linkage } \\
\text { benefits(B5) } 0.198\end{array}$} & Job contribution rate of employees(C13) 0.040 \\
\hline & & & $\begin{array}{c}\text { Agricultural product processing and conversion } \\
\text { capabilities(C14) } 0.158\end{array}$ \\
\hline
\end{tabular}

\section{Conclusion and potential analysis}

The AHP method was used to measure 14 relevant indicators, and the agricultural product processing industry of Gansu Province was ranked in 23 provinces according to each indicator, as shown in Table 2.

(1) The raw material resources of characteristic agricultural products are large in quantity and high in quality

The waste water discharge per unit output value of the agricultural product processing industry in Gansu Province is at the middle level in the country. The agricultural product planting and breeding link has a special natural ecological environment, and the use of chemical fertilizers and pesticides is lower than the national average. It can provide a steady stream of highquality raw materials for the agricultural product processing industry in Gansu Province. Guaranteed.

(2) Great room for adjustment of energy resource consumption structure

The coal consumption per unit output value and the waste gas emissions per unit output value of the agricultural product processing industry in Gansu Province are relatively large. It ranks in the bottom $10 \%$ of the national province rankings, while the total energy consumption per unit output value ranks 9 th. The energy 
substitution rate needs to be improved, and there is a lot of room for the adjustment of the internal structure of the overall energy consumption in Gansu Province.

(3) Realize high potential value of industrial linkage

The ranking of the ratio of the total output value of the agricultural product processing industry to the total agricultural output value of Gansu Province is at the end of the national level, while the total output value of agricultural products ranks relatively higher. There is a lot of room for improvement in the development capacity of the agricultural product processing industry, which is mainly reflected in the intensive processing, comprehensive utilization processing and staple food processing of grain and characteristic agricultural products. The development of the industrial chain and value chain of the agricultural product processing industry on the basis of large-scale agriculture has great value in realizing the development of industrial linkage.

(4) Great opportunities to tap economic development benefits

The main business income, total profit, total output value, and profit rate of assets of the agricultural product processing industry in Gansu Province are all at the lowest level in the country. It can do a lot to solve the contradiction between the decentralized production and centralized processing of agricultural products, to realize the secondary appreciation of agricultural by-products, to make up for the lack of famous brands, low grades, and weak overall competitiveness, and to transform the rich agricultural resources into economic development benefits. Great opportunity.

(5) There is a large room for improving the output of scientific and technological achievements

The R\&D personnel input intensity of the agricultural product processing industry in Gansu Province ranks fourth. Compared with other industries, R\&D personnel have preliminary advantages in the agricultural product processing industry, and the R\&D funding input intensity is ranked 15th, which can basically meet the funding needs of R\&D activities. However, the patent output rate is at the end. Under the current R\&D resource input level, the overall scientific and technological achievements output rate and conversion rate have a lot of room for improvement.

Table 2 Ranking of various indicators of the agricultural product processing industry in Gansu Province

\begin{tabular}{|c|c|c|c|c|c|}
\hline Closeness & Rank & Closeness & Rank & Closeness & Rank \\
\hline \multicolumn{2}{|c|}{ Total } & \multicolumn{2}{|c|}{ Wastewater discharge per unit output value } & \multicolumn{2}{|c|}{ Waste gas emission per unit output value } \\
\hline 0.439 & 19 & 1.881 & 14 & 3.898 & 22 \\
\hline \multicolumn{2}{|c|}{$\begin{array}{l}\text { Coal consumption per unit } \\
\text { output value }\end{array}$} & \multicolumn{2}{|c|}{$\begin{array}{l}\text { Electricity consumption per unit output } \\
\text { value }\end{array}$} & \multicolumn{2}{|c|}{$\begin{array}{l}\text { Total energy consumption per unit outpu } \\
\text { value }\end{array}$} \\
\hline 0.472 & 21 & 0.556 & 11 & 0.949 & 9 \\
\hline \multicolumn{2}{|c|}{ Industrial output } & \multicolumn{2}{|c|}{ Main business income } & \multicolumn{2}{|c|}{ Return on assets } \\
\hline 0.280 & 22 & 0.640 & 23 & 1.562 & 22 \\
\hline \multicolumn{2}{|c|}{ Total profit } & \multicolumn{2}{|c|}{ R\&D expenditure input intensity } & \multicolumn{2}{|c|}{ R\&D personnel input intensity } \\
\hline 1.600 & 23 & 1.243 & 15 & 4.560 & 23 \\
\hline \multicolumn{2}{|c|}{ Patent output rate } & \multicolumn{2}{|c|}{ Job contribution rate of employees } & \multicolumn{2}{|c|}{$\begin{array}{l}\text { Agricultural product processing and } \\
\text { conversion capabilities }\end{array}$} \\
\hline 1.888 & 4 & 1.549 & 22 & 6.320 & 23 \\
\hline
\end{tabular}

\section{References}

1. Wang Baoguo. Survey on the demand for mechanization technology and equipment for the production of advantageous and characteristic agricultural products in Linxia County, Gansu Province [J]. Agricultural Machinery, 2020 (04): 106-107+110.

2. 2.Xu Tiantian. Research on the Circulation Mode of Agricultural Products in Gansu Province under the Internet Background[J]. Logistics Engineering and Management, 2020, 42(01): 14-16.

3. Huang Xiaying. The development dilemma and strategy of Gansu agricultural product supply chain based on "precise poverty alleviation and Internet +"[J]. China Business Forum, 2020(22):107-108.

4. The Ministry of Agriculture deploys the national agricultural product processing industry brand creation work $[\mathrm{J}]$. Shanghai Rural Economy,
2017(06): 48.

5. Wang Bao, Wang Penglong, Xu Bingxin, Wang Qinhua. The status quo and countermeasures of brand construction of characteristic and advantageous agricultural products in Gansu Province[J]. Jiangsu Agricultural Sciences, 2020, 48(07): 9-13. 